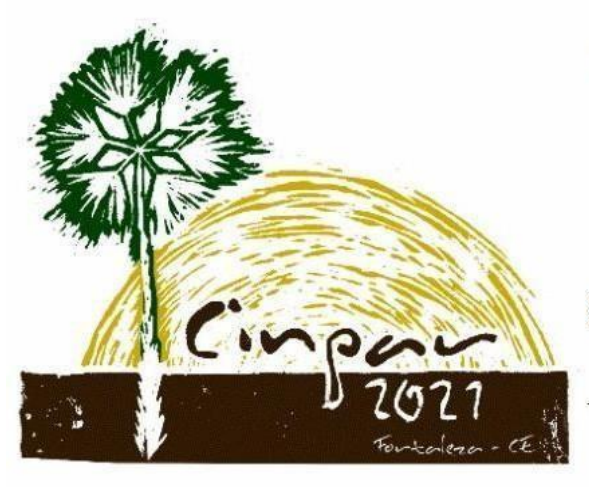

XVII Congresso Internacional sobre Patologia e Reabilitação das Construções

XVII Congreso Internacional sobre Patología y Rehabilitación de las Construcciones

XVII International Conference on Pathology and Constructions Rehabilitation

FORTALEZA (Brasil), 3 a 5 de junho de 2021 https://doi.org/10.4322/CINPAR.2021.142

\title{
Análise das manifestações patológicas em elementos estruturais - Estudo de caso em um edifício na cidade de Fortaleza - CE
}

\section{Analysis of pathological manifestations in structural elements - Case study in a building in the city of Fortaleza - CE}

\author{
Dyaloisio ARAÚso ${ }^{1}$, Caio DIÓGENES ${ }^{2}$, Douglas SOUZA ${ }^{3}$, Adiláyne MENDES ${ }^{4}$, Daniele FERNANDES ${ }^{5}$, \\ Matheus ARAÚjO 6 \\ 1 KTEK Soluções de Engenharia, Fortaleza, Brasil, ktekengenharia@gmail.com \\ 2 Universidade Federal do Ceará, Russas, Brasil, caiod.silva2@gmail.com \\ 3 Universidade Federal do Ceará, Russas, Brasil, douglassampaio@alu.ufc.br \\ 4 Universidade Federal do Ceará, Russas, Brasil, adilaynemendes@gmail.com \\ 5 Universidade Federal do Ceará, Russas, Brasil, danny.fern@alu.ufc.br \\ 6 Universidade Federal do Ceará, Russas, Brasil, m.rib.araujo@gmail.com
}

\begin{abstract}
Resumo: Ultimamente, a construção civil manifesta-se bem mais diversificada nos seus sistemas construtivos para a execução de uma edificação, sendo ainda na sua maioria feita de concreto armado. No Brasil, as edificações têm demostrando uma redução na sua duração, especialmente por problemas nas suas estruturas, sejam em vigas, pilares ou lajes, onde as patologias atacam com maior agressividade. Apesar das estruturas de concreto armado serem bastante utilizadas, os estudos sobre manifestações patológicas que nelas ocorrem são escassas e dificulta sua identificação e escolha da melhor solução. O presente trabalho tem por finalidade avaliar o laudo técnico realizado em um edifício em Fortaleza, mostrando as causas geradoras da anomalia estrutural nas vigas, identificadas através de diagnósticos sensoriais, ensaios de esclerometria e de Capacidade de Suporte Califórnia (CBR). Foi feito uma inspeção estrutural de manifestações patológicas, mostrando seus riscos na edificação, embasados nas anomalias construtivas, que são aquelas que prejudicam o desempenho, a funcionalidade, a vida útil prevista, a utilização, decorrentes de problemas de projetos, execução, especificação de materiais, informações defeituosas sobre manutenção, uso e operação de sistemas. Para a investigação da resistência do solo, foi realizado o ensaio de CBR, e subsequente outros ensaios na parte estrutural, para a avaliação das manifestações patológicas, encontradas nas estruturas, como fissuras leves, medianas e críticas, e, além disso, erros no dimensionamento estrutural, que não estavam de acordo com as normas técnicas. Dessa forma, em função das características geológicas do solo e do carregamento aplicado pela edificação, a estrutura está sofrendo um recalque diferencial, devido à ineficiência do solo/estrutura em suportar as cargas oriundas da edificação e, também, sofre de deterioração dos elementos estruturais, especialmente nas vigas, necessitando com brevidade de intervenção para uma recuperação estrutural.
\end{abstract}

Palavras-Chaves: Manifestações patológicas. Vigas. Estrutural. Concreto armado. 
Abstract: Lately, civil construction has manifested itself much more diversified in its construction systems for the execution of a building, being still mostly made of reinforced concrete. In Brazil, buildings have shown a reduction in their duration, especially due to problems in their structures, whether in beams, pillars or slabs, where pathologies attack more aggressively. Despite the fact that reinforced concrete structures are widely used, studies on pathological manifestations that occur in them are scarce and make it difficult its identification and choice of the best solution. The present work aims to evaluate the technical report carried out in a building in Fortaleza, showing the causes of structural anomaly in the beams, identified through sensory diagnoses, sclerometry tests and California Support Capacity (CBR). A structural inspection of pathological manifestations was carried out, showing its risks in the building, based on constructive anomalies, which are those that impair performance, functionality, expected useful life, use, resulting from problems with projects, execution, material specification, defective information on maintenance, use and operation of systems. For the investigation of soil resistance, the CBR test was carried out, and subsequent other tests on the structural part, for the evaluation of pathological manifestations, found in the structures, such as light, medium and critical cracks, and, in addition, design errors structural, which were not in accordance with technical standards. Thus, due to the geological characteristics of the soil and the load applied by the building, the structure is undergoing a differential settlement, due to the inefficiency of the soil / structure in supporting the loads arising from the building and also suffering from deterioration of the structural elements, especially in beams, requiring intervention quickly for structural recovery.

Keywords: Pathological manifestations; Beams; Structural; Reinforced concrete.

\section{Introdução}

Helene e Andrade (2010), expõe que na história recentemente tem demonstrado que ainda é vantajoso pesquisar, projetar, dosar, construir, sempre procurando obter a melhor utilidade do concreto, esse versátil material de construção, explorando seu elevado desempenho e usando-o corretamente.

De acordo ainda com esse autor, a afirmação da busca por novas ferramentas, aperfeiçoamento de técnicas na área da construção civil foi primordial na última década, nos acresceu um conhecimento inovador e profissionais mais capacitados. Isso não se limitou apenas na fase de projeto e construção, mais também nos trouxe a solução para grande parte das doenças construtivas, ou seja, no estudo das manifestações patológicas.

Capello et al. (2010) frisou que a origem dos problemas patológicos pode ser decorrente de uma etapa do processo construtivo, ou de um conjunto de fatores, não apenas de uma falha isolada. Da mesma forma que as manifestações patológicas podem ocasionar danos arquitetônicos, estéticos, funcionais e estruturais. Realça ainda os danos que acarretam desde o desconforto, prejuízos financeiros, inclusive colocando vidas em risco.

De acordo com o previsto na NBR 15575 - Edificações habitacionais - Desempenho (ABNT, 2013), uma obra tem vida útil de no mínimo 50 anos, entretanto segundo Antunes (2010), a negligência quanto a utilização de materiais de má qualidade, a falta de técnicas construtivas, visto que, várias etapas são executadas inadequadamente, omissão das especificações de projeto, bem como a cultura de não fazer a manutenção das edificações, são fatores determinantes para o surgimento das patologias.

A pesquisa na área de Patologia é de suma importância para o desenvolvimento e aperfeiçoamento da construção civil. Contudo, diante da complexidade do diagnostico que envolve diversos fatores, desde a região em que se situa a edificação, as características locais, ou mesmo pular etapas da execução, as mesmas em sua maior parte dão origem as manifestações patológicas e a necessidade das possíveis correções.

Portanto, as pesquisas quanto as incidências patológicas e o trabalho em questão são ferramentas de conhecimento indispensáveis que contribuem para atestar uma edificação segura, com conforto e vida útil longa. Demostrando que o estudo das patologias nas edificações é de grande relevância no cenário atual, na 
busca de qualidade dos processos construtivos e na melhoria da habitabilidade e durabilidade das edificações.

\section{Metodologia}

A realização deste trabalho baseou-se nas normas e legislações pertinentes a inspeção predial, com ênfase nos sistemas estruturais. Buscando evitar falhas no processo, a efetivação deste estudo de caso, teve como normas fundamentais, a norma de Inspeção predial nacional do IBAPE (2012) e a orientação técnica para inspeção predial e auditoria técnica IBRAENG (2015).

\subsection{Vistoria Técnica}

Inicialmente, foi realizada uma visita de caráter preliminar buscando colher informações técnicas fundamentais para a realização da inspeção predial. Essa visita contou com a presença do síndico e do zelador do edifício.

A primórdio, foi realizado um mapeamento bidimensional do empreendimento para a identificação dos elementos estruturais, visto que a edificação possivelmente não dispõe de quaisquer projetos referentes à estrutura. Através do mapeamento dimensional, foi realizado o levantamento das manifestações patológicas existentes para se avaliar as causas geradoras das anomalias.

\subsection{Ensaios Realizados}

A princípio, seria realizado um ensaio de extração de corpo de prova para determinar a resistência mecânica do elemento estrutural, no entanto, devido ao estado de deterioração da estrutura, foi realizado o ensaio de esclerometria. A esclerometria é um método não-destrutivo que mede a dureza superficial do concreto, fornecendo elementos para a avaliação da qualidade do concreto endurecido.

Os ensaios foram realizados em cinco pontos, sendo dois pontos (P01 e P02) na viga V02, um ponto (P03) na viga V22, um ponto(P04) na viga V29 e um ponto na viga V30, conforme indicado pelas Figuras 1 e 2.

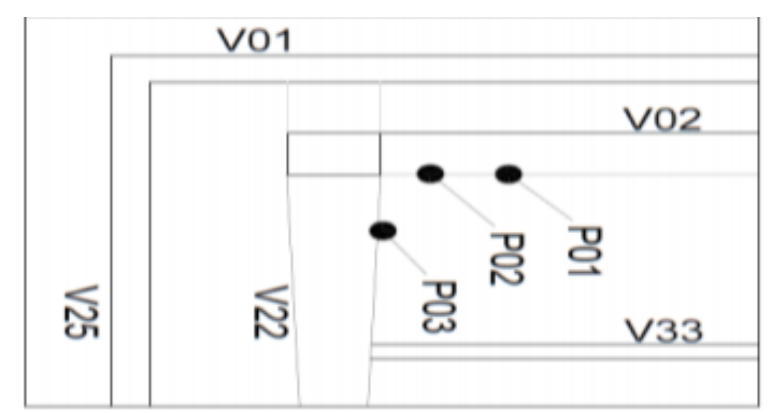

Figura 1 - Pontos de ensaio de esclerometria na V22 e V02. Fonte: Próprio autor (2021).

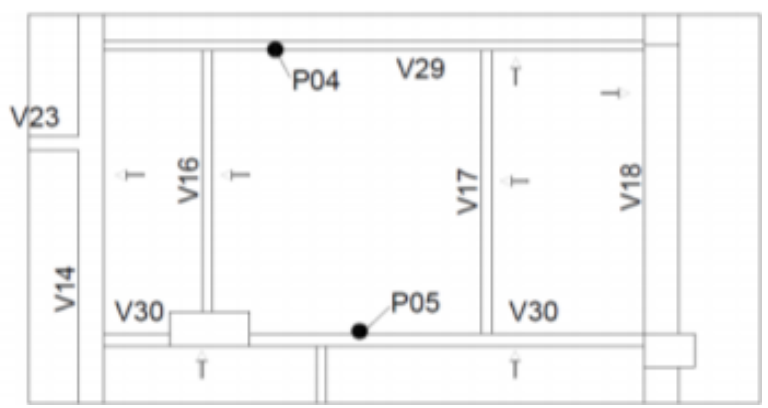

Figura 2 - Pontos de ensaio de esclerometria na V29 e V30. Fonte: Próprio autor (2021).

Para a investigação da resistência mecânica do solo, foi realizado o ensaio Capacidade de Suporte Califórnia (CBR). A coleta do solo para a realização do ensaio em laboratório, foi realizado a 4 metros da viga 04 (V04) e a 0,5m da borda do Pilar (P1), conforme identificado na Figura 3. 


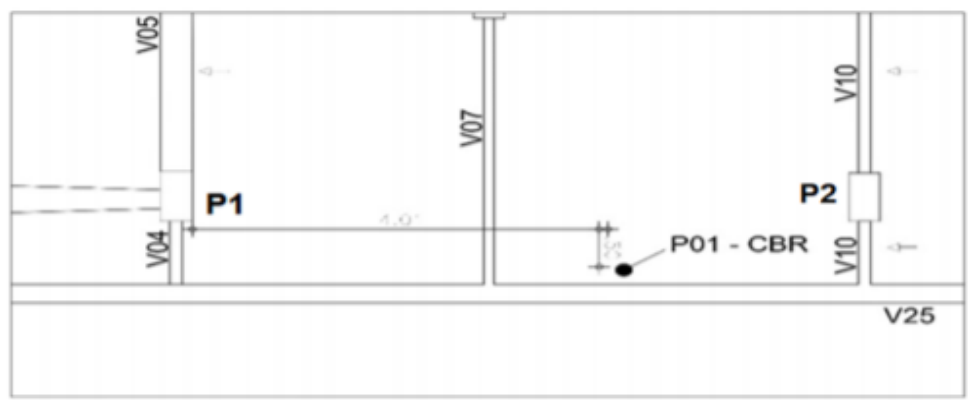

Figura 3 - Local de coleta de amostra de solo para ensaio CBR. Fonte: Próprio autor (2021).

\section{Resultados}

As manifestações patológicas referem-se as fissuras/rachaduras apresentadas na fachada lateral direita do condomínio Vivenda Serena. A Figura 4 apresenta a edificação com as manifestações patológica identificadas, no qual temos, em 1, fachada lateral direita, em 2, fissuras próximas ao pavimento cobertura, em 3 e 4 fissuras próximo aos vãos de janela da unidade habitacional do segundo pavimento. Ocasionadas possivelmente por movimentações térmicas e ausência de juntas de dilatação.

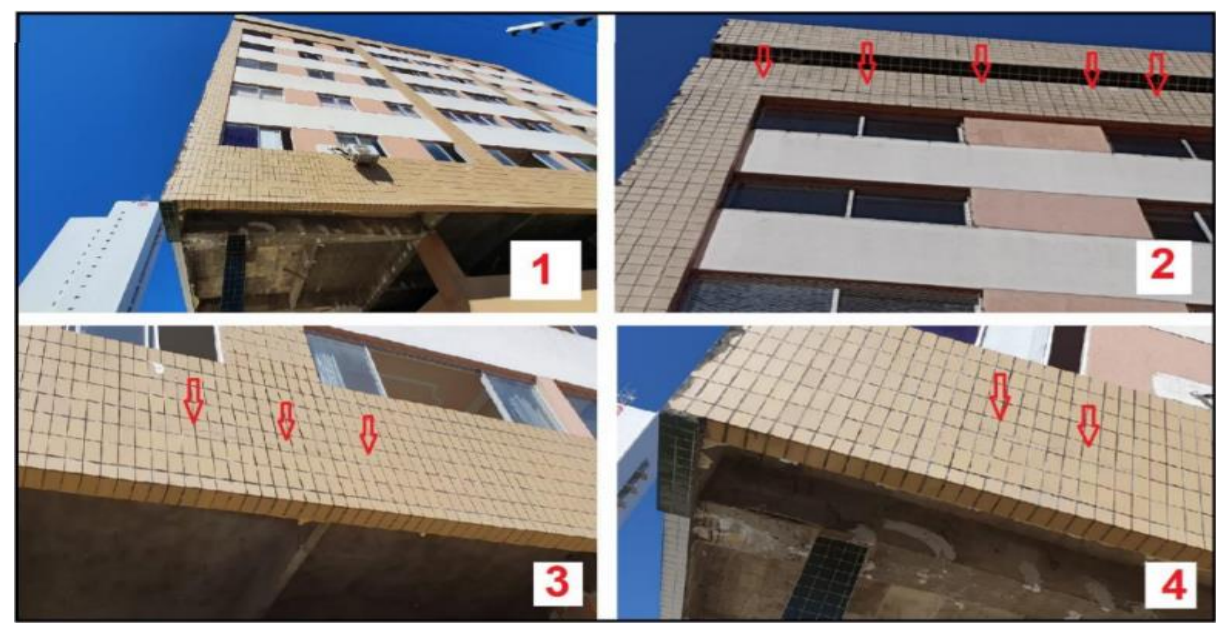

Figura 4 - Anomalias na fachada lateral direita . Fonte: Próprio autor (2021).

Após o mapeamento bidimensional das vigas da edificação, foi realizado o levantamento das manifestações patologicas presentes para se avaliar as causas geradoras das anomalias, conforme apresentado na Tabela 1.

Tabela 1 - Delimitação e possíveis causas das fissuras. Fonte: Próprio autor (2021). 


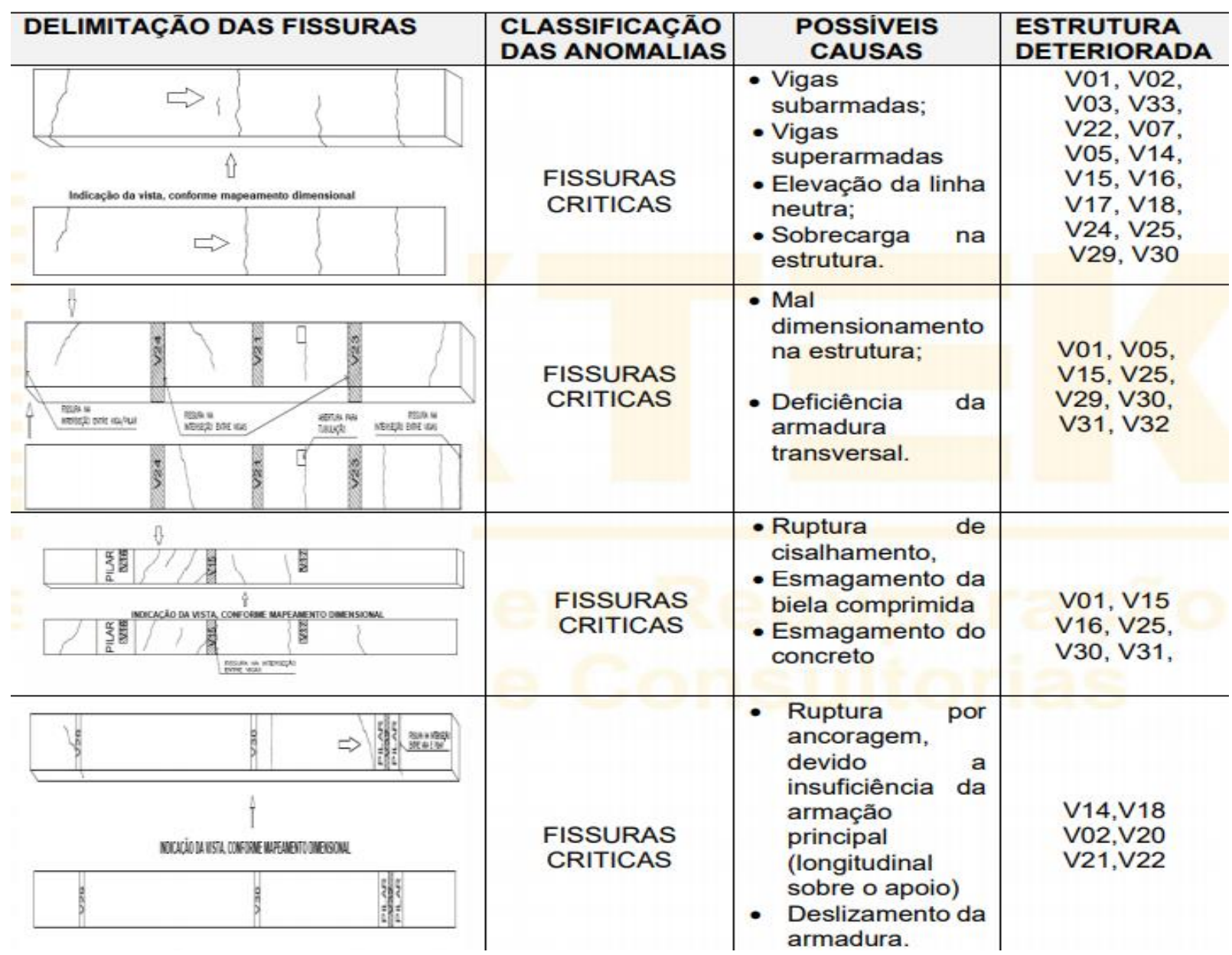

Após o mapeamento de fissuras, onde observa-se quais os pontos mais criticos do prédio, verifica-se a estimativa de resistência mecânica à compressão obtida nos ensaios realizados pela IPMATE, está apresentada na Tabela 2.

Tabela 2 - Resultado dos ensaios realizados pela IPMATE. Fonte: Próprio autor (2021).

\begin{tabular}{|c|c|c|}
\hline Pontos & Peças ensaiadas & Resistencia a compressão superficial obtida (Mpa) \\
\hline P01 & V02 & 28,49 \\
\hline P02 & V02 & 29,89 \\
\hline P03 & V22 & 24,33 \\
\hline P04 & V29 & 29,31 \\
\hline P05 & V30 & 30,53 \\
\hline
\end{tabular}

Através dos resultados obtidos na análise de escloremetria apresentados na Tabela 2, obtivemos uma resistência média para o concreto de $28,31 \mathrm{Mpa}$, possuindo uma divergência de resistência na viga V22 em relação as demais.

Portanto, verifica-se que durante o processo executivo da obra, provavelmente não houve um controle tecnológico adequado do concreto, e consequentemente pode ser um agravante para a evolução das anomalias estruturais da edificação, no entanto, a resistência mecânica se encontra dentro dos padrões usuais de acordo com as normas e a prática de mercado, descrito na Tabela 3.

Tabela 3 - Resistência de concreto estrutural. Fonte: Próprio autor (2021). 


\begin{tabular}{|c|l|}
\hline Resistência mecânica a compressão & \multicolumn{1}{|c|}{ Descrição } \\
\hline 15 MPA & $\begin{array}{l}\text { Resistência mecânica a compressão } \\
\text { mínima aceitável para concreto estrutural } \\
\text { no ano de 1980 NBR 6118 (ABNT,1980). } \\
\text { Atualmente, só pode ser usada em } \\
\text { fundações. }\end{array}$ \\
\hline 20 MPA & $\begin{array}{l}\text { Resistência mínima do concreto estrutural } \\
\text { a partir da NBR 6118 (ABNT, 2003) }\end{array}$ \\
\hline 30 Mpa & $\begin{array}{l}\text { Resistencia mínima utilizada usualmente } \\
\text { na prática de mercado, na atualidade. }\end{array}$ \\
\hline
\end{tabular}

\subsection{Ensaio de Resistência do Solo}

A Figura 5 apresenta o processo da coleta da amostra do solo, no qual está subdividade em 4 etapas.
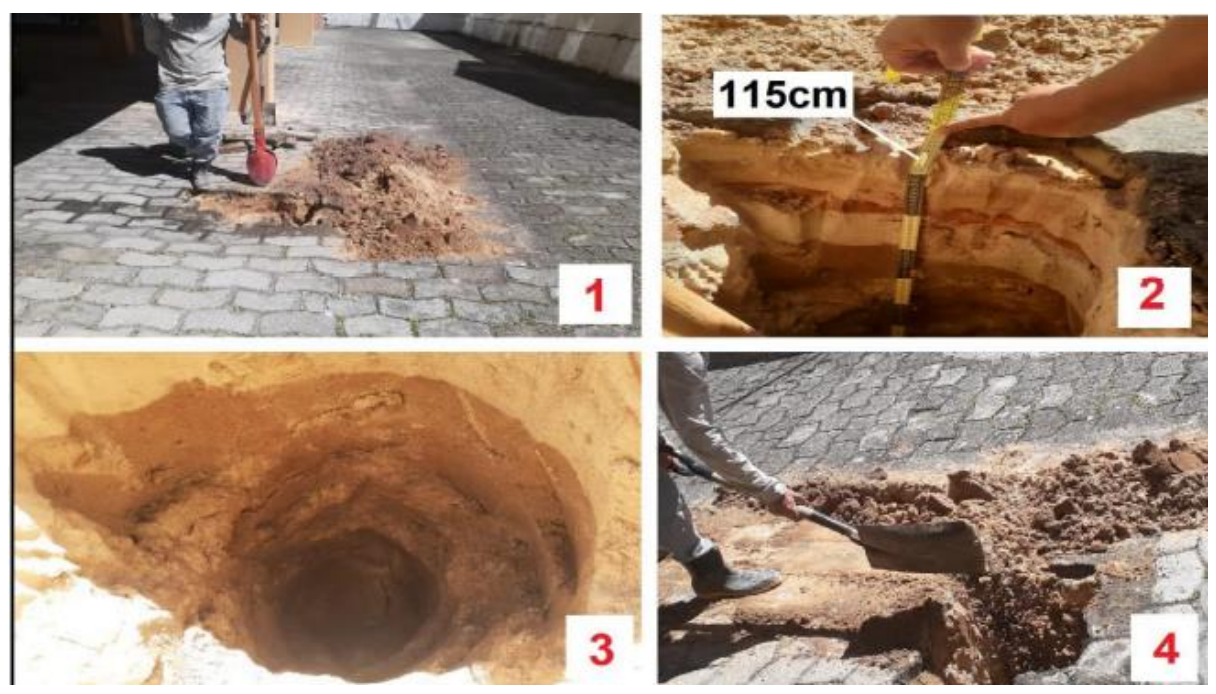

Figura 5 - Processo de coleta da amostra, no qual temos, em 1, escavação, em 2, medição e coleta da amostra, em 3 , exposição do solo até a camada coletada, em 4, reaterro do local. Fonte: Próprio autor (2021).

Durante a execução da coleta da amostra, identificou-se que o solo apresenta as características de um solo siltoso amarelado até a profundidade de $115 \mathrm{~cm}$, e possivelmente uma resistência mecânica insuficiente em suportar as cargas oriundas da edificação, conforme a resistência apontada no ensaio de CBR.

Além disso, o solo provavelmente tem características geológicas de deformação inadequado para suportar as cargas da edificação, visto que possivelmente as anomalias são oriundas de um recalque diferencial, devido as características gerais de anomalias apresentadas na edificação.

\subsection{Anomalias Construtivas da Edificação}

Durante a avaliação estrutural realizada no condomínio Vivenda Serena, foram identificadas algumas anomalias construtivas no qual difere dos processos construtivos apontado na NBR 6118 (ABNT,2014). 

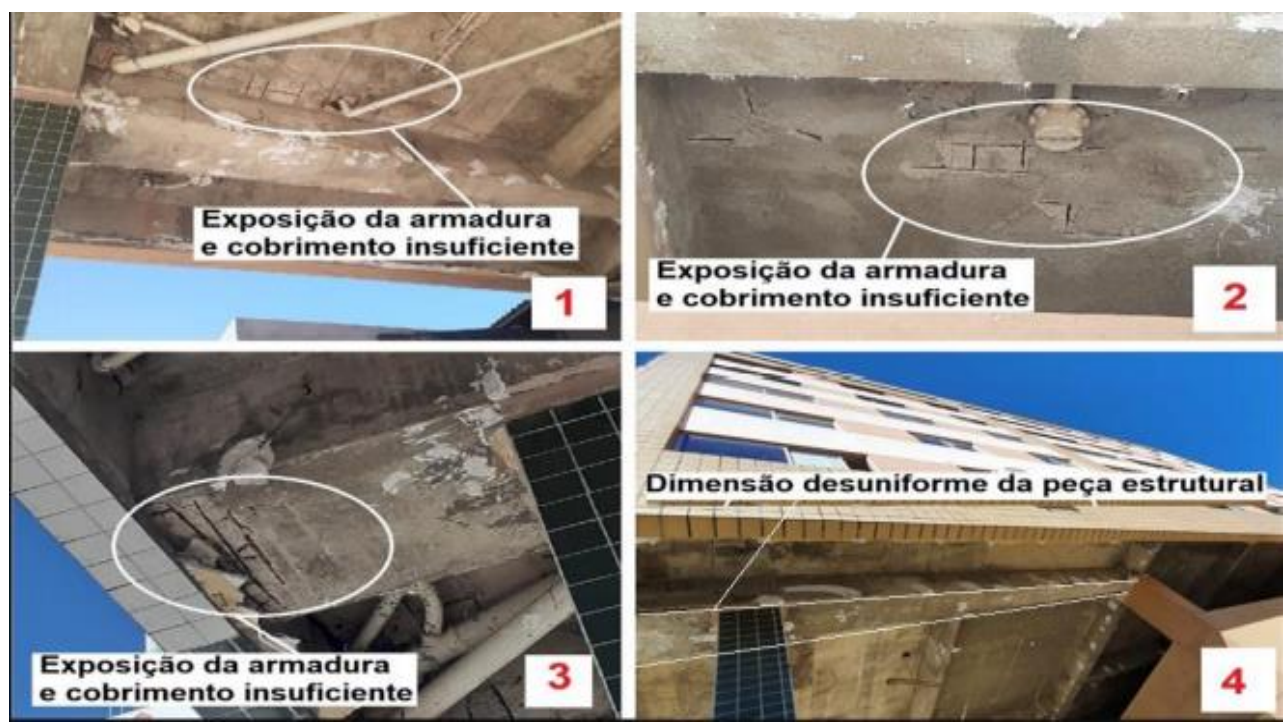

Figura 6 - Anomalias construtivas identificadas na edificação, no qual temos, em 1, 2 e 3 exposições da armadura e cobrimento insuficiente do elementro estrutural, em 4, dimensão desuniforme da peça estrutural. Fonte: Próprio autor (2021).

De acordo com as práticas construtivas e as recomendações apontadas nas NBR's de estrutura de concreto armado atual e anteriores, não se prever reduções das seções dos elementos estruturais em pontos distintos do mesmo elemento estrutural, conforme apresentado na Figura 6, no elemento 4.

Além disso, segundo a NBR 6118 (ABNT,2014), os elementos estruturais de concreto armado devem conter um cobrimento mínimo de $20 \mathrm{~mm}$ para lajes e $25 \mathrm{~mm}$ para vigas e pilares, de acordo com a classe de agressividade do ambiente. A Figura 7 apresenta os cobrimentos mínimos da norma vigente.

Tabela 4 - Cobrimentos Mínimos. Fonte: NBR 6118 (2014).

\begin{tabular}{|c|c|c|c|c|c|c|}
\hline & & \multirow{3}{*}{$\begin{array}{l}\text { Componente ou } \\
\text { elemento }\end{array}$} & \multicolumn{4}{|c|}{ Classe de agressividade ambiental (Tabela 6.1) } \\
\hline \multirow{2}{*}{\multicolumn{2}{|c|}{ Tipo de estrutura }} & & I & II & III & IV c \\
\hline & & & \multicolumn{4}{|c|}{$\begin{array}{l}\text { Cobrimento nominal } \\
\mathrm{mm}\end{array}$} \\
\hline \multirow{3}{*}{\multicolumn{2}{|c|}{ Concreto armado }} & Laje $b$ & 20 & 25 & 35 & 45 \\
\hline & & Viga/pilar & 25 & 30 & 40 & 50 \\
\hline & & $\begin{array}{l}\text { Elementos } \\
\text { estruturais em } \\
\text { contato com o solo d }\end{array}$ & & & 40 & 50 \\
\hline \multirow{2}{*}{\multicolumn{2}{|c|}{$\begin{array}{c}\text { Concreto } \\
\text { protendido a }\end{array}$}} & Laje & 25 & 30 & 40 & 50 \\
\hline & & Viga/pilar & 30 & 35 & 45 & 55 \\
\hline \multicolumn{7}{|c|}{$\begin{array}{l}\text { a Cobrimento nominal da bainha ou dos fios, cabos e cordoalhas. O cobrimento da armadura passiva deve } \\
\text { respeitar os cobrimentos para concreto armado. }\end{array}$} \\
\hline \multicolumn{7}{|c|}{$\begin{array}{l}\text { Para a face superior de lajes e vigas que serão revestidas com argamassa de contrapiso, com revestimentos } \\
\text { finais secos tipo carpete e madeira, com argamassa de revestimento e acabamento, como pisos de } \\
\text { elevado desempenho, pisos cerâmicos, pisos asfálticos e outros, as exigências desta Tabela podem ser } \\
\text { substituídas pelas de } 7.4 .7 .5 \text {, respeitado um cobrimento nominal } \geq 15 \mathrm{~mm} \text {. }\end{array}$} \\
\hline c & \multicolumn{6}{|c|}{$\begin{array}{l}\text { Nas superfícies expostas a ambientes agressivos, como reservatórios, estações de tratamento de água e } \\
\text { esgoto, condutos de esgoto, canaletas de efluentes e outras obras em ambientes química e intensamente } \\
\text { agressivos, devem ser atendidos os cobrimentos da classe de agressividade IV. }\end{array}$} \\
\hline d & \multicolumn{6}{|c|}{$\begin{array}{l}\text { No trecho dos pilares em contato com o solo junto aos elementos de fundação, a armadura deve ter } \\
\text { cobrimento nominal } \geq 45 \mathrm{~mm} \text {. }\end{array}$} \\
\hline
\end{tabular}

Segundo a NBR 6118 (ABNT,1980), item 6.3.3.1, "Qualquer barra da armadura, inclusive de distribuição, de montagem e estribos, deve ter cobrimento de concreto pelo menos igual ao seu diâmetro, mas não menor que $20 \mathrm{~mm}$ para concreto aparente no interior de edifícios".

\section{Considerações Finais}

Análise das manifestações patológicas em elementos estruturais-Est. de caso de um ed. em Fortaleza-CE 
Através da inspeção estrutural e dos ensaios realizados na edificação, pôde-se constatar que as fissurações apresentadas ocorrem possivelmente por erros no dimensionamento estrutural, devido a não observância das recomendações apontadas nas NBRs.

Dessa forma, em função das características geológicas do solo e do carregamento aplicado pela edificação, a estrutura está sofrendo um recalque diferencial, devido a ineficiência do solo/estrutura em suportar as cargas oriundas da edificação.

Uma possível solução para as anomalias supracitadas neste documento, é a utilização de fibras de carbono para um reforço nos elementos estruturais. A princípio, a utilização da fibra de carbono, apresenta-se como a solução mais viável economicamente, devido as características apresentadas pela edificação.

Para a solução do recalque diferencial, recomenda-se o aumento da seção transversal do elemento de fundação dos pilares, com o objetivo de reduzir as tensões aplicada no solo, e, consequentemente, a redução da área de influência do bulbo de tensões. Além disso, pode-se fazer a substituição do solo existente por outro, com características necessárias para suportar a deformação/carregamento da edificação, conforme proposto no laudo CBR realizado pela IPMATE. No entanto, necessita-se verificar a viabilidade econômica para execução.

\section{Refências Bibliograficas}

ANTUNES, Giselle Reis. Estudo de Manifestações Patológicas em Revestimento de Fachada em BrasíliaSistematização da Incidência de Casos. Dissertação de Mestrado em Estruturas e Construção Civil, Publicado E.DM-001A/10, Departamento de Engenharia Civil, e Ambiental, Universidade de Brasília, Brasília- DF, 178p. Associação Brasileira de Normas Técnicas. NBR 15575:2013: Edificações habitacionais - Desempenho. Rio de Janeiro. 2013

Associação Brasileira de Normas Técnicas. NBR 6118/2014, Projeto de estruturas de concreto Procedimento. Rio de janeiro. 20140.

Associação Brasileira de Normas Técnicas. NBR- 6502/1995, Rocha e solos- Terminologia;. Rio de janeiro. 1995.

Associação Brasileira de Normas Técnicas NBR 8953/2015, Concreto para fins estruturais. Rio de janeiro. 2015.

Associação Brasileira de Normas Técnicas NBR 6122/2010, Projeto e execução de fundações. Rio de janeiro. 2010.

Associação Brasileira de Normas Técnicas ABNT NBR 9895/2017 - Solo - Índice de suporte Califórnia (ISC) Método de ensaio. Rio de janeiro. 2015.

Associação Brasileira de Normas Técnicas. NBR7584/2012: Concreto endurecido - Avaliação da dureza superficial pelo esclerômetro de reflexão - Método de ensaio. Rio de janeiro. 2012.

CAPELLO, A. et al. Patologia das Fundações. 2010. 115f. Monografia (Bacharel em Engenharia Civil) Faculdade Anhanguera de Jundiaí, Jundiaí, 2010.2 Disponível em: <https://pt.scribd.com/doc/54137409/PATOLOGIA-DE-FUNDACOES-TCC>. Acesso em: 10 jan. 2021.

HELENE, Paulo; ANDRADE, Tibério. Concreto de Cimento Portland. In: ISAIA, Geraldo Cechella. Materiais de Construção Civil e Princípios de Ciência e Engenharia de Materiais. 2. ed. São Paulo: Ibracon, 2010. Cap. 29. p. 905-944. 